\title{
Study of Drug Resistant Pulmonary Tuberculosis
}

\author{
Lt Col RB Deoskar*, Dr B Sengupta ${ }^{+}$, Col KE Rajan*, Lt Col MS Barthwal ${ }^{* *}$, Col JJJ Falleiro, sM $^{++}$, \\ Brig SK Sharma, vsM"\#
}

\begin{abstract}
Background: Drug resistance has emerged as a major problem in management of pulmonary tuberculosis (PT) with increase in its incidence.

Methods: Sixty patients who presented to a tertiary referral chest centre with drug resistant PT were included in the study out of 835 clinically diagnosed cases of PT treated between January 2000 and May 2002. They were studied to see the incidence, pattern of drug resistance and response to treatment.

Results: $7.2 \%$ of the clinically diagnosed cases of PT had drug resistance and $14.8 \%$ of the 403 strains of mycobacterium tuberculosis (MTB) tested were resistant to one or more antitubercular drugs (ATD). 40 cases (66.7\%) had initial resistance and acquired resistance was seen in $20(33.3 \%)$ out of the 60 cases of drug resistant PT. Single drug resistance was observed in 21 cases $(35 \%)$, two drug resistance in $19(31.7 \%)$ and $20(33.3 \%)$ cases showed resistance to three or more drugs. Individual drug resistance breakup was : INH(H) - 36(8.9\%), Rifampicin (R)- 38(9.4\%), Ethambutol (E) - 14(3.5\%), Streptomycin (S) - 34(8.4\%), Pyrazinamide (Z) - 2(0.5\%), Ciprofloxacin (C) - 2(0.5\%), Ethionamide $(\mathrm{N})-2(0.5 \%)$, Cycloserine - 1(0.3\%) and Kanamycin - 1(0.3\%). $98.3 \%$ showed sputum conversion after starting reserve drugs. Average period of sputum conversion was 10 weeks. $3.3 \%$ were HIV positive.

Conclusion: Incidence of drug resistance was not as high as reported by some other workers and majority of the cases showed satisfactory outcome.
\end{abstract}

MJAFI 2005; 61 : 245-248

Key Words: Drug resistant pulmonary tuberculosis

\section{Introduction}

$\mathrm{D}$ rug resistance has emerged as a major problem in management of pulmonary tuberculosis (PT). Not only has the incidence of drug resistance gone up, there have also been reports that it is commoner in HIV positive individuals, and vice versa [1]. The two main causes for the development of drug resistance are nonadherence to prescribed therapy and use of inadequate treatment regimens. Important risk factors for drug resistance include previous treatment with anti tubercular drugs (ATD) and contact with a person who has infectious drug resistant tuberculosis.

In cases of multi-drug resistant (MDR) tuberculosis, not only is the cost of treatment higher, the duration of treatment is also longer and side effects due to drugs are more. Outcome of these cases is also not as good as drug-susceptible tuberculosis. Furthermore, the public health danger posed by a patient with infectious MDR tuberculosis cannot be under estimated.

In India, reliable data on drug resistant tuberculosis are not available, due to lack of culture facilities in most centres and improper reporting system. The figures reported by some tertiary care hospitals and referral centres are very high and may not be representative of the general population. In the Armed Forces, more reliable figures are available as all personnel with PT are being given fully supervised sanatorium treatment in specified centers where culture facilities are available and follow up is possible. The present study was undertaken to study the incidence, pattern of drug resistance and response to treatment in case of drug resistant PT.

\section{Material and Methods}

The study was carried out in a tertiary referral chest centre between January 2000 and May 2002. All cases with clinical, bacteriological or radiological evidence of PT admitted to the centre during the period of study, with clinical and bacteriological features of drug resistance were included in the study. They were all given fully supervised sanatorium treatment and reserve ATD was added based on culture and sensitivity reports. Age, sex, past history of ATD and HIV status were noted in all cases.

\footnotetext{
${ }^{* * *}$ Classified Specialist (Medicine and Respiratory Medicine) ${ }^{+}$Ex-PG Resident (Respiratory Medicine), "Senior Adviser (Medicine and Respiratory Medicine), Military Hospital, Cardio Thoracic Centre, Pune-40, ++Commanding Officer, 4033 Field Ambulance, C/o 56 APO. \#\#) Deputy Director General, Armed Forces Medical Services (P), Office of the DGAFMS, Ministry of Defence, New Delhi.
}

Received : 22.10.2003; Accepted : 08.11.2004 
Sputum for acid fast bacillus (AFB) by Ziehl Neelsen stain was done fortnightly in all cases and sputum for mycobacterium tuberculosis (MTB) culture and sensitivity on Lowenstein Jensen (LJ) media was done monthly in all cases. Identification and subsequent biochemical tests were performed in accordance with the manual of laboratory methods (1987), Tuberculosis Research Centre (ICMR), Chennai [2]. Indirect susceptibility tests were carried out by incorporating required concentration of the drugs in the media which was inoculated by taking standardized inoculum. Control strain H 37 RV was set up with each batch of drug sensitivity testing.

The strains were defined resistant if a growth of $>20$ colonies was observed at the following drug concentrations INH (H) - MIC > $1 \mathrm{mg} / \mathrm{l}$, Streptomycin (S) - Resistance ratio $\geq 8$, Rifampicin (R) - MIC $>64 \mathrm{mg} / \mathrm{l}$, Ethionamide (N) - MIC $>$ $114 \mathrm{mg} / \mathrm{l}$ and Ciprofloxacin (C) - MIC $>16 \mathrm{mg} / \mathrm{l}$.

\section{Results}

Of the 835 cases of PT clinically diagnosed and treated, 403 (48.3\%) grew MTB and 304 (36.5\%) were AFB positive. Of the 403 strains of MTB tested, 60 (14.8\%) were resistant to one or more ATD. These accounted for $7.2 \%$ of the clinically diagnosed and treated cases of PT. The study included 52 males and 8 female patients. Mean age of the patients was 31.6 years. Out of the 60 resistant strains, acquired drug resistance was observed in $20(33.3 \%)$ and initial drug resistance in $40(66.7 \%)$ cases, constituting $5.0 \%$ and $9.9 \%$ of the total MTB isolates respectively. 15(25\%) of the 60 cases with drug resistance had received regular and complete treatment with ATD in the past. $6(10 \%)$ patients gave history of close contact with a known case of PT. The remaining 34 $(56 \%)$ denied such history in the past (Table 1).

In 46 out of 60 (76.7\%) patients, sputum was positive on smear and culture examination, whereas in $14(23.3 \%)$ the smear was negative for AFB but growth of MTB was obtained on culture. Antibiotic susceptibility revealed single drug resistance in 21 cases (35\%), two drug resistance in 19 (31.7\%) and $20(33.3 \%)$ showed resistance to three or more drugs. Individual drug resistance breakup was: H-36 (8.9\%), R-38 (9.4\%), E-14 (3.5\%), S-34 (8.4\%), Z-2(0.5\%), C-2 (0.5\%), N-2 $(0.5 \%)$, Cycloserine- $1(0.3 \%)$ and Kanamycin $-1(0.3 \%)$ for the 403 strains of MTB tested. The pattern of drug resistance is as per Table 2. There were 24 cases of MDR, i.e. $6 \%$ of the 403 strains tested. 34 of these cases required treatment with

Table 1

Past history of drug resistant cases $(n=60)$

\begin{tabular}{|c|c|c|}
\hline Past history of the patients & $\begin{array}{l}\text { No. of drug } \\
\text { resistant strains }\end{array}$ & $\begin{array}{l}\% \text { to drug } \\
\text { resistant strains }\end{array}$ \\
\hline $\begin{array}{l}\text { a. Relapse (after complete } \\
\text { treatment in the past) }\end{array}$ & 15 & 25.0 \\
\hline $\begin{array}{l}\text { b. History of irregular } \\
\text { treatment with ATD }\end{array}$ & 5 & 8.3 \\
\hline $\begin{array}{l}\text { c. History of close contact } \\
\text { with a known case of TB }\end{array}$ & 6 & 10.0 \\
\hline $\begin{array}{l}\text { d. No history of exposure } \\
\text { to ATD/PT patient }\end{array}$ & 34 & 56.7 \\
\hline
\end{tabular}

reserve drugs, while 26 responded to first line drugs. Reserve ATD used were N-27, C-25, PAS-14, Kanamycin-14, Ofloxacin8, Cycloserine-3, Amikacin-1, Sparfloxacin-1 and Azithromycin-1. 59 patients $(98.3 \%)$ showed sputum conversion after treatment. Average period of sputum conversion was 10 weeks. 11 patients developed adverse reactions to drugs. Gastritis was seen in six, two due to $\mathrm{N}$ and in four due to PAS. Giddiness was seen in three patients on Kanamycin and drug rash was seen in two patients on Z. One case was subjected to left lower lobectomy for extensive bronchiectasis with intractable haemoptysis. One case continues to be sputum positive in spite of taking reserve ATD for more than a year. Mortality was nil. Only two cases were HIV positive out of the 60 cases of drug resistant PT (3.3\%). The patients are still under follow up. Average period of follow up was 8.7 months. Eight patients were lost to follow up.

\section{Discussion}

Incidence of drug resistance has been $11.7 \%$ to $17.1 \%$ in studies carried out at our centre between April 1992 and July 1998 [3-6]. The incidence was found to be $13.7 \%$ in a study carried out at $\mathrm{MH}$ Dehradun between 1998 to 1999 [7]. Majority of patients in these studies were serving personnel but a few families who received outpatient treatment after an initial period of hospitalization were also included. In our study the incidence of drug resistance was $14.8 \%$. The incidence of drug resistance at our centre is lower than that reported from other centres in India, where total resistance was $22.2 \%$ to $34.0 \%$ [8,9].

Earlier studies from our centre showed a higher percentage of single drug resistance than our study in which $35 \%$ of the cases showed single drug resistance. $65 \%$ showed resistance to two or more drugs in our study which was more than the earlier studies done at our centre. The incidence of MDR in other centres in India is 0 to $6 \%$ except in Gujarat where a high level was observed $(11.4-18.5 \%)$ [10,11,12].

Level of resistance to Rifampicin in our study was

\section{Table 2}

Pattern of drug resistance in cases $(n=60)$

\begin{tabular}{|c|c|c|c|}
\hline 1 drug & Strains resistant to 2 drugs & \multicolumn{2}{|c|}{3 and more drugs } \\
\hline $\mathrm{H}-7(1.7 \%)$ & SR-6 $(1.5 \%)$ & SHR-9 & $(2.2 \%)$ \\
\hline R-7 (1.7\%) & SH-6 (1.5\%) & SHRE-7 & $(1.7 \%)$ \\
\hline S-4 $(1.0 \%)$ & HR-5 (1.2\%) & HRE-1 & $(0.2 \%)$ \\
\hline E-2 $(0.5 \%)$ & RE-1 $(0.2 \%)$ & SHRZENK-1 & $(0.2 \%)$ \\
\hline C-1 $(0.2 \%)$ & SE-1 $(0.2 \%)$ & $\begin{array}{l}\text { HRPAS } \\
\text { Cycloserine }\end{array}$ & $(0.2 \%)$ \\
\hline Z-0 & & $\mathrm{N}-1$ & \\
\hline $\mathrm{N}-0$ & & EZC-1 & $(0.2 \%)$ \\
\hline $1 \quad(5.2 \%)$ & $(4.7 \%)$ & 20 & $(5.0 \%)$ \\
\hline
\end{tabular}

(Figures in brackets indicate \% of drug resistant strains to total MTB isolates) 
$9.4 \%$, which was higher than in earlier studies from our centre [3-6]. The emergence of Rifampicin resistance after introduction of short term chemotherapy has been noted by other workers also. Most of these cases are due to acquired resistance [10-17]. Level of INH resistance $(8.9 \%)$ has also increased at our centre as compared to earlier studies, while Streptomycin resistance (8.4\%) has not shown any increase [3-6].

Studies from United States have shown higher rates of drug resistance in HIV positive persons and vice versa $[1,18,19]$. In the present study only $3.3 \%$ of the cases of drug resistant PT were HIV-positive. In a earlier study at one of the service hospitals all 28 MDR-PT cases were HIV negative [20].

The increasing role of resectional surgery in MDRPT has been highlighted by Iseman [21]. Only one of our cases was subjected to surgery. In the study by Rosha et al also, only one case was subjected to resectional surgery [20].

Drug resistance is associated with a higher risk of treatment failure and relapse [13,17,2-25]. Mortality in patients with MDR-TB is also higher $[25,26]$. In the present study mortality was nil and $98.3 \%$ showed sputum conversion after starting treatment, in an average of 10 weeks. The main reasons for good response to treatment in our patients were better compliance of treatment due to hospitalization during the first few months, regular follow-up, availability of ATD, no delay in starting appropriate regimen once drug resistance was diagnosed, availability of culture facilities, more disciplined patients and highly nutritious diet provided to patients.

Adverse reactions to ATD were observed in 11 of our patients with drug resistant PT while Rosha et al did not observe any adverse drug reactions in their patients with MDR-PT [20]. Only 34 of our 60 cases with drug resistant PT were managed with reserve ATD. Ethionamide, Ciprofloxacin, PAS, Kanamycin and Ofloxacin were found to be effective with very few side effects.

Only one patient showed unsatisfactory response to treatment in our study. The 8 patients lost to follow-up were all families of soldiers who could not be admitted for a prolonged period. However all of them had become sputum negative and they were advised to take treatment from the nearest service hospital.

\section{References}

1. Gordin FM, Nelson, Matts JP, et al. The impact of human immunodeficiency virus infection on drug resistant tuberculosis. Am J Respir Crit Care Med 1996; 154:1478-83.

2. Manual of laboratory methods, Tuberculosis Research Center (ICMR), Chennai 1987.
3. Jena J, Panda BN, Nema SK, Ohri VC, Pahwa RS. Drug resistance pattern of mycobacterium tuberculosis in a chest diseases hospital of Armed Forces. Lung India 1995;13:56-9.

4. Jena J, Nema SK, Panda BN. Drug resistant tuberculosis - the emerging scenario. Medical Journal Armed Forces India 1996;52:87-90.

5. Panda BN, Jena J, Rai SP, Chatterji RS. Supervised chemotherapy in pulmonary tuberculosis and emergence of drug resistance in cases of relapse. Ind J Tub 2000;163-6.

6. Chand K, Tewari SC, Varghese SJ. Prevalence of drug resistant tuberculosis in Armed Forces - study from a tertiary referral chest diseases hospital at Pune. Medical Journal Armed Forces India 2000;56:130-4.

7. Jena J, Panda BN. A comparative study of drug resistance pattern of M tuberculosis in (I) People of Hilly terrain / Terai belt of Himalayan foot - hills (II) People of rest of India and (III) People of Tibetan Origin Ind J Tub 2001;48:160.

8. ICMR: Prevalence of drug resistance in patients with pulmonary tuberculosis presenting for the first time with symptoms at chest clinic in India. Part-II. Findings in urban clinics among patients giving no history of previous chemotherapy. Ind J Med Res 1969;57:823:35.

9. Gopi PG, Vallishayee RS, Appe Gowda BN, et al. A tuberculosis prevalence survey based on symptom questioning and sputum examination. Ind J Tub 1997;44:171-80.

10. Trivedi SS, Desai SC. Primary antituberculosis drug resistance and acquired rifampicin resistance in Gujarat, India. Tubercle 1988;69:37-42.

11. Sophia Vijay, VH Balasangameshwara, PS Jagannatha, P Kumar. Initial drug resistance among tuberculosis patient under DOTS programme in Bangalore city. Ind J Tub 2004; 51:17:22.

12. Tuberculosis Research Centre (ICMR), Chennai. Trends in initial drug resistance over three decades in a rural community in South India. Ind J Tub 2003;50:75-86.

13. Paramsivan CN, Chandrasekaran V, Santha T, Sudarsanam NM, Prabhakar R. Bacterio-logical investigations for short course chemotherapy under the tuberculosis programme in two districts in India. Tub Lung Disease 1993;74:23-7.

14. Chandrasekaran S, Jagota P, Chaudhuri K. Initial drug resistance to anti-tuberculosis drugs in urban and rural district tuberculosis programme. Ind J Tub 1992;39:171-5.

15. Chandrasekaran S, Chauhan MM, Rajalakshmi R, Chaudhuri $\mathrm{K}$, Mahadev B. Initial drug resistance to anti-tuberculosis drugs in patients attending an urban district tuberculosis centre. Ind J Tub 1990;37:215-6.

16. Gupta PR, Singhal B, Sharma TN, Gupta RB. Prevalence of initial drug resistance in tuberculosis patients attending a chest hospital. Ind J Med Res 1993;97:102-3.

17. Jain NK, Chopra KK, Prasad G. Initial and acquired isoniazid and rifampicin resistance to $\mathrm{M}$ tuberculosis and its implications for treatment. Ind J Tub 1992;39:121-4.

18. Edlin BR, Tokars JI, Grieco MH, et al. An out break of multi drug resistant tuberculosis among hospitalized patients with the acquired immunodeficiency syndrome. N Eng J Med 1992;326:1514-21.

19. Busillo C, Lessnau KD, Sanjana V, et al. Multi drug resistant Mycobacterium tuberculosis in patients with human immunodeficiency virus infection. Chest 1992;101:797-801.

20. Rosha D, Dandona PK, Jayaswal R. Multi drug resistant 
pulmonary tuberculosis - a clinical profile of 28 cases. Medical Journal Armed Forces India 1997;53:159-62.

21. Iseman MD. A clinician's guide to tuberculosis, $1^{\text {st }}$ ed, Lippincott Williams and Wilkins 2000.

22. Mathew R, Santha T, Parthasarathy R, et al. Response of patients with initially drug resistant organisms to treatment with short - course chemotherapy. Ind J Tub 1993;40:119-23.

23. Mitchison DA, Nunn AJ. Influence of initial drug resistance on the response to short-course chemotherapy of pulmonary tuberculosis. Am Rev Respir Disease 1986; 133:423-30.
24. Solomon N, Perlman DC, Friedmann P, Buchstein S, Kreiswirth BN, Mildvan D. Predictors and outcome of multi drug resistant tuberculosis. Clin Infect Disease 1995;21:1245-52.

25. Park MM, Davis AL, Schluger NW, Cohen H, Rom WN. Outcome of MDR- TB patients, 1983-1993: Prolonged survival with appropriate therapy. Am J Respir Crit Care Med 1996;153:317-24.

26. Iseman MD. Treatment of multi drug resistant tuberculosis. $\mathrm{N}$ Engl J Med 1993; 329:784:91.

\title{
Quiz
}

\section{Radiological Quiz}

\author{
Surg Capt J D'Souza*, Surg Cmde SK Mohanty,sm, vsm ${ }^{+}$, Surg Cdr IK Indrajit"
}

MJAFI 2005; $61: 248$

Key Words : Abdominal pain

\begin{abstract}
A 57-year old man presented to MI Room Awith acute onset lower abdominal pain of six hours duration. There was no history of surgery. He was afebrile. There was mild abdominal tenderness and increased tympanic bowel sounds. General examination showed an averagely built and nourished individual with board like rigidity of abdomen. Supine radiograph of abdomen were performed immediately which is displayed below in Fig. 1.

What is your diagnosis?
\end{abstract}

Answer to the quiz - page 273

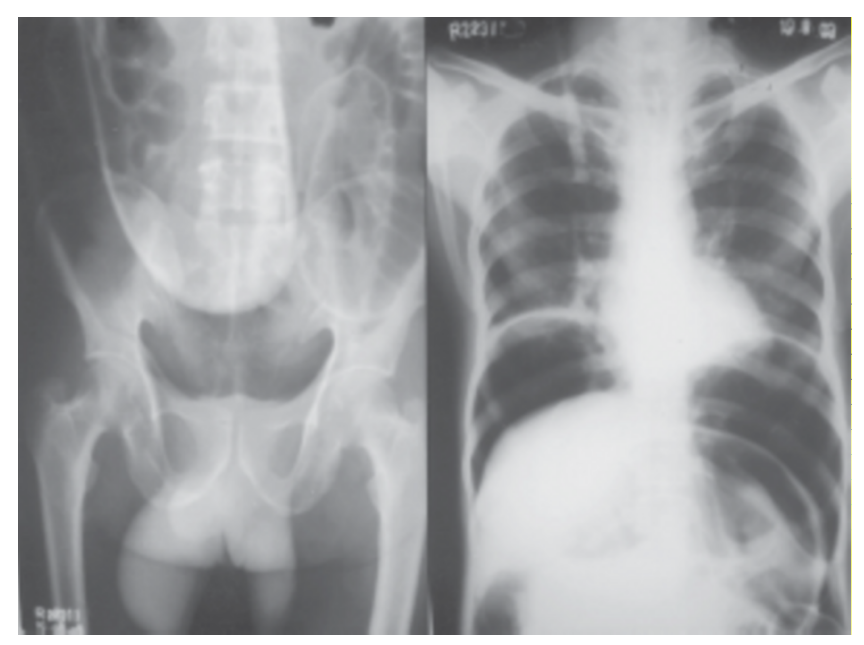

Fig. 1 : Plain abdomen radiographs

"Senior Advisor,\#Classified Specialist (Radiodiagnosis and Imaging), INHS Asvini, Colaba, Mumbai, ${ }^{+}$CMO, HQ Southern Naval Command, Kochi.

Received : 28.02.2004; Accepted : 04.09.2004 